\title{
A PROSPECTIVE STUDY TO COMPARE THE RESPONSE AND TOXICITY IN PATIENTS TREATED WITH CONCOMITANT BOOST RADIOTHERAPY VERSUS CONVENTIONAL RADIOTHERAPY IN (LA-HNSCC)
}

\author{
Manish Verma1, Arpit Jain², Vinay Shivhare ${ }^{3}$, Sudhir Katariya ${ }^{4}$, Allwin George ${ }^{5}$, Minaal Iyer ${ }^{6}$, Ashish Malviya ${ }^{7}$, Abhishek Pratap Singh ${ }^{8}$ \\ ${ }_{1}^{1}$ Assistant Professor, Department of Radiotherapy, Government Cancer Hospital, Indore, Madhya Pradesh, India. \\ ${ }^{2} 3^{\text {rd }}$ Year Postgraduate Student, Department of Radiotherapy, Government Cancer Hospital, Indore, Madhya Pradesh, India. \\ 3 Senior Resident, Department of Radiotherapy, Government Cancer Hospital, Indore, Madhya Pradesh, India. \\ ${ }^{4}$ Specialist Medical Officer, Department of Radiotherapy, Government Cancer Hospital, Indore, Madhya Pradesh, India. \\ ${ }_{5}^{5}$ Senior Resident, Department of Radiotherapy, Government Cancer Hospital, Indore, Madhya Pradesh, India. \\ ${ }^{6}$ Senior Resident, Department of Radiotherapy, Government Cancer Hospital, Indore, Madhya Pradesh, India. \\ 73rd Year Postgraduate Student, Department of Radiotherapy, Government Cancer Hospital, Indore, Madhya Pradesh, India. \\ ${ }^{82}{ }^{\text {nd }}$ Year Postgraduate Student, Department of Radiotherapy, Government Cancer Hospital, Indore, Madhya Pradesh, India. \\ ABSTRACT
}

\section{BACKGROUND}

Head and neck malignancies require multidisciplinary teamwork approach to achieve a considerable outcome. Adjuvant or definitive radiotherapy plays a central role in management of locally advanced head and neck cancer. Concomitant boost radiotherapy has shown a significant benefit over conventional radiotherapy in various studies done earlier. A second daily fraction given during the radiation schedule in CBT allows for an aggressive fractionation regimen with an advantage of limiting the volume of normal mucosa exposed. We wanted to compare the outcome of concomitant boost radiotherapy versus conventional radiotherapy in patients with locally advanced head and neck squamous cell carcinoma (LA-HNSCC).

\section{MATERIALS AND METHODS}

A total of 80 patients with locally advanced head and neck SCC were enrolled and followed prospectively. This study was conducted in the Department of Radiotherapy, MGM medical college Indore. All patients were randomly assigned into Group I (concomitant boost radiotherapy) and Group II (conventional radiotherapy), with 40 patients each, to a total dose of 70 Gy using conventional Co-60 machine.

\section{RESULTS}

Complete response (CR) was seen in 28 patients (70\%) of Group I and 25 patients (62.5\%) of Group II. 12 patients (30\%) of Group I and 14 patients (35\%) of Group II had partial response. One patient in Group II did not respond to the treatment. Rate of acute reactions were slightly higher in patients treated with Concomitant boost radiotherapy. Patients were followed for a median duration of 14 months (range 6-18 months). Recurrence developed in five patients in Group I and eight patients in Group II, who had complete response.

\section{CONCLUSION}

CBT can be a good alternative to conventional RT regimen with good tolerability, better results but with slight increase in acute reactions. It also minimises the overall treatment time and workload.

\section{KEY WORDS}

Concomitant Boost Technique, Head and Neck Carcinoma, Squamous Cell Carcinoma

HOW TO CITE THIS ARTICLE: Verma M, Jain A, Shivhare V, et al. A prospective study to compare the response and toxicity in patients treated with concomitant boost radiotherapy versus conventional radiotherapy in (LA-HNSCC). J. Evolution Med. Dent. Sci. 2019;8(12):868-871, DOI: 10.14260/jemds/2019/193

\section{BACKGROUND}

Malignancies of the head and neck region is emerging as a significant health related issue in India, with a distinct socioeconomic background. Most of the cases in India reported with locally advanced stage because of illiteracy, poverty, scarcity of adequate health infrastructure.

'Financial or Other Competing Interest': None.

Submission 19-12-2018, Peer Review 07-03-2019,

Acceptance 13-03-2019, Published 25-03-2019.

Corresponding Author:

Dr. Vinay Shivhare,

Senior Resident,

R. N. 18, Intern Block,

Medical Boy Hostel,

MGMMC, Indore, Madhya Pradesh, India.

E-mail: shivharevinay@yahoo.com

DOI: $10.14260 /$ jemds $/ 2019 / 193$
Management of Locally advanced head and neck cancer requires skilled multidisciplinary approach. Extensive surgery with Radiation therapy and chemotherapy plays a key role in treatment.

Major issue in locally advanced cancer treated with radiation is the proliferation of clonogenic cells. To deal with this problem various accelerated fractionation radiotherapy techniques emerged. Most of these regimens were associated with significant acute toxicities. This problem was not seen with a type of accelerated fractionation, Concomitant boost radiotherapy (CBT) because it reduces the overall volume of tissue that is irradiated with high doses. Overall duration of treatment also reduced to five weeks from seven weeks.

With this aim, we conducted a study to see the toxicity and efficacy of CBT over conventional RT. In CBT, a large field that includes the primary lesion and possible microscopic disease site receives a total dose of 70 Gy in Five weeks along with a second daily boost dose to a small field that includes 
only primary lesion and the clinically palpable lymph. The small field treated to 50 Gy with a interval gap of 4-6 hr between two daily fractions. As the area receiving accelerated fractionation RT is very small, there is very little enhancement in acute reactions. Also, the dose per fraction being the same, late reactions remain unaffected.

In CBT, the boost dose to the small field can be given in three ways. It can be given either at the beginning, with the last fractions or throughout the treatment duration. We delivered the boost dose at the start of the treatment, considering better patient compliance.

\section{MATERIALS AND METHODS}

We conducted a Prospective Randomised controlled study in which a total of 80 patients were registered in the Department of Radiotherapy, MGM medical college Indore between Jan 2014 to and April 2015. The inclusion criteria were biopsy confirmed squamous cell carcinoma of the oral cavity or oropharynx, TNM stage III and IV, treatment naive patient, KPS $>70 \%$, no underlying medical illness and no distant metastasis at the time of diagnosis. Because a very large lymph node group i.e. N3, is difficult to include in a single small boost field, it was excluded from the study.

Patients with distant metastasis, lactating and pregnant mother were also excluded. A complete work up including a $\mathrm{CBC}, \mathrm{RFT}, \mathrm{CXR}$, lateral oblique views of the mandible or OPG and dental prophylaxis were done before treatment started. The study was conducted after the protocol was approved by the institution's ethics review board. Sampling was purposive with the recruitment target of 40 subjects per arm.

The patients were randomised into two groups using computer-generated procedure. Patients and tumour characteristics in two groups are depicted in [Table - 1] Group I $(n=40)$ were treated with radiotherapy in the form of CBT. In this group, the large field received a total dose of 50 Gy (as 200 cGy/fraction) daily for five days a week for five weeks, followed by the dose of 20 Gy in 12 fractions (as 167 cGy/ fraction) to the small field as a boost dose, in the beginning of the treatment, at an interval of 4-6 hrs.

Group II $(n=40)$ received a total dose of 70 Gy using conventional fractionation schedule (200 cGy per fraction), five days a week. Field reduced anteriorly to cord off the dose after 46 Gy.

During the treatment patients were reviewed every week for symptoms of acute reactions and tutor response. After completion of treatment, those with complete disappearance of disease at the primary site and the lymph nodes were assigned as complete response (CR). Reduction in More than $50 \%$ of disease at either site was considered as partial response (PR); patients having less than $50 \%$ response were considered as having no response (NR). Patients were reviewed monthly afterwards, and those with recurrence or residual disease were selected for salvage surgery or palliative chemotherapy or care. Median duration of followup was 14 months (Range 6 to 18 months).

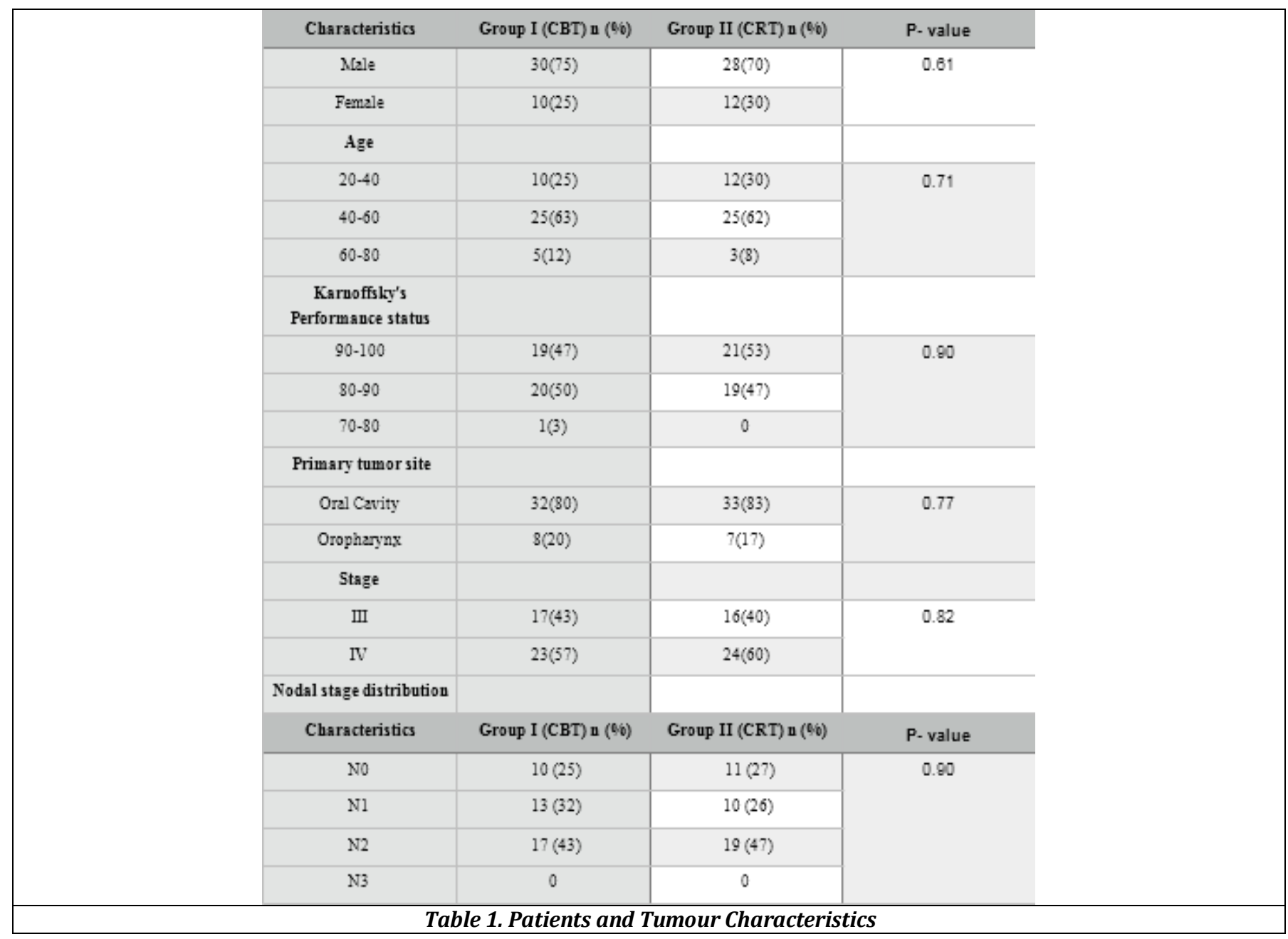


Categorical variables were expressed as counts and percentages and compared between groups by Pearson's Chi- square test or Fisher's exact test as appropriate. A p-value of $<0.05$ was taken as significant. Data were analysed using the statistical software SPSS for windows (version 19.0).

\section{RESULTS}

Out of 40, 28 patients in Group I had CR (70\%) and 12 had PR (30\%). None of the patients had NR or disease progression. In Group II, 25 patients out of 40 had CR (62.5\%) and 14 patients had PR (35\%) and one patient showed NR. [Table - 2] shows the comparison of tumour response. Incidence of acute toxicity in patients reviewed weekly, is depicted in [Table - 3]; the graded according to the RTOG criteria. All patients stood the treatment well without any interruptions.

Four patients in group I and seven patients in group II have shown recurrence during follow up.

\begin{tabular}{|c|c|c|c|c|c|c|c|}
\hline Sites & \multicolumn{3}{|c|}{ GROUP I (CBT) } & \multicolumn{3}{c|}{ GROUP II (CRT) } & P value \\
\hline & CR & PR & NR & CR & PR & NR \\
\hline Buccal Mucosa & 11 & 5 & 0 & 11 & 7 & 0 & 0.23 \\
\hline Gingivo-alveolus & 7 & 3 & 0 & 6 & 2 & 0 & 0.79 \\
\hline Oral Tongue & 2 & 1 & 0 & 2 & 2 & 0 & 0.66 \\
\hline Lip & 2 & 1 & 0 & 2 & 1 & 0 & 1.00 \\
\hline Oropharynx & 6 & 2 & 0 & 4 & 2 & 1 & 0.46 \\
\hline
\end{tabular}

\begin{tabular}{|c|c|c|c|c|c|c|c|c|c|}
\hline \multicolumn{7}{|c|}{ GROUP I (CBI) } & \multicolumn{7}{c|}{ GROUP II (CRT) } \\
value \\
\hline \\
\hline
\end{tabular}

\section{DISCUSSION}

Conventional boost radiotherapy stood well with comparable results to the conventional fractionation, as is studied in several studies till date[1],[2],[3],[4] The concomitant boost technique took advantage of reducing chances of accelerated repopulation during conventional fractionation irradiation of head and neck tumours by irradiating mucosa to twice daily treatment.[5],[6] The primary objective of this study was to compare the tolerability, efficacy and practicality of CBT over conventional RT in locally advanced head and neck cancer.

$70 \%$ in Group I and $62.5 \%$ in group II showed complete response. While remaining 30\% in group I and $40 \%$ in group II showed partial response. $2.5 \%$ patients in group II showed no response. There was no statistically significant difference between the two arms for CR (P - value $=0.23)$. 5 patients in group I and 8 patients in group II showed local recurrence with a median duration of $8 \& 6$ months respectively. It shows that altered fractionation CBT reduces the recurrence rate and improves the overall survival outcome.
Acute toxicities were observed weekly during the treatment in both arms. The most common acute toxicities were nausea and vomiting, mucositis, skin reaction due to radiation, xerostomia, dysphagia, and dysgeusia. The grading was done according to the CTCAE criteria version 4.0.

All patients tolerated the treatment well and no person was failed to complete the treatment regimen. Incidence of Acute reactions were high in the CBT group as compare to conventional arm and grade III mucositis was seen maximally in the 2nd week in CBT arm. Twelve patients in Group I develops Grade III mucositis, required hospitalisation and IV fluids. Grade III mucositis persisted for 3-15 days and relieved subsequently with proper hydration and symptomatic management. No patients needed radiation treatment gap. In Group II, ten out of 40 patients developed Grade III mucositis during the treatment course, for which they were admitted and were well managed with IV fluids. In this study results were comparable with the previous studies. $[7],[8],[9],[10]$ 


\section{CONCLUSION}

Concomitant boost radiotherapy, a variant of accelerated fractionation which took the advantage of possible differential radiobiological susceptibility between tumour and normal mucosal cells, can be a reasonable alternative to conventional fractionation radiotherapy with improved tumour control rate, with a slight increase in acute normal tissue toxicity.

\section{REFERENCES}

[1] Knee R, Fields RS, Peters LJ. Concomitant boost RT for advanced squamous cell carcinoma of head and neck. Radioth Oncol 1985;4(1):1-7.

[2] Ang KK, Peters LJ, Weber RS, et al. Concomitant boost radiotherapy schedules in the treatment of carcinoma of oropharynx and nasopharynx. Int Jour of Radiation Oncol Biol and Phys 1990;19(6):1339-45.

[3] Kaanders JH, Van Daal WA, Hoogenraad WJ, et al. Accelerated fractionation radiotherapy for laryngeal cancer, acute and late toxicity. Int J Rad Oncol Biol and Phys 1992;24(3):497-503.

[4] Yu E, Souhami L, Guerra J, et al. Accelerated fractionation in inoperable non-small cell lung cancer. A phase I/II study. Cancer 1993;71(9):2727-31.
[5] Peters LJ, Ang KK, Thomas HD Jr. Accelerated fractionation in the radiation treatment of head and neck cancer: a critical comparison of different treatment strategies. Acta Oncol 1988;27(2):185-94.

[6] Withers HR, Taylor JM, Maciejewski B. The hazard of accelerated tumor clonogen repopulation during radiotherapy. Acta Oncol 1988;27(2):131-46.

[7] Schmidt-Ullrich RK, Johnson CR, Wazer DE, et al. Accelerated superfractionated irradiation for advanced carcinoma of the head and neck concomitant boost technique. Int Jour of Radiation Oncol Biol and Phys 1991;21(3):564-68.

[8] Bujko K, Skoczylas JZ, Bentzen SM, et al. A feasibility study of concomitant boost radiotherapy for patients with cancer of the supraglottic larynx. Acta Oncol 1993;32(6):637-40.

[9] Srivastava K, Srivastava M. Concomitant boost radiotherapy vs. conventional radiotherapy in advanced oral cavity and oropharynx cancers. Indian J Radiol Imaging 2001;11(3):127-30.

[10] Meshram SD, Kamble KM, Diwan AK, et al. Conventional vs. concomitant boost radiotherapy with concurrent cisplatin in advanced head and neck cancer. J Can Res Ther 2015;11(4):770-4. 